\title{
Design of Organizational Memory Management Model in the Education System in Mazandaran Province
}

\author{
Neda Esmaeli \\ Department of Educational Management, Sari Branch, Islamic Azad University, Sari, Iran \\ Reza Yosefi Saeidabadi* \\ Department of Educational Management, Sari Branch, Islamic Azad University, Sari, Iran \\ *Corresponding Author: Reza yosefi saeidabadi
}

\author{
Doi:10.5901/mjss.2016.v7n3s3p20
}

\begin{abstract}
Organizational memory is a system that in addition to store the existing knowledge in organization, always provides and reminds useful information to the organization staff on time and develops and improves re-use of knowledge created by the organization staff. Organizations need to develop and adapt a model of organizational memory in implementation of their affairs; the challenges of management are identified and showed by this developed model. That is called organizational memory management. This study has been conducted for the aim to design an organizational memory management model in the Education System in Mazandaran Province. Statistical population is 40823 persons of the Education in Mazandaran Province. The sampling method is stratified random and for sample determination 381 persons selected as a sample based on a Cochran formula. The data gathering tool has been conducted by researcher made questionnaire. Content validity was used to determine the validity, and its reliability was examined by Cronbach's alpha coefficient, and the amount of 0.801 was calculated. Research data was analyzed in two descriptive statistical levels to determine the frequency and percentage mean, standard deviation - tilt and elongation, minimum and maximum, and diagrams were analyzed in the inferential statistics level from multivariate regression test, factor analysis and internal consistency. Analysis of the results showed that the organizational memory management model in the education system is a linear structure. The important suggestion is that individual knowledge components and the staff memory of organization culture, organization technology, organizational communication, organization background, change and transformation of the organization and organization structure are the builder components of organizational memory management model in the education system.
\end{abstract}

Keywords: organization memory, organizational memory management, organizational memory management model, the education system

\section{Introduction}

The creation and improve organizational memory is one of the educated intellectual resources management methods. Organizations should keep knowledge about past efforts and environmental conditions in their memory. When your organization teaches something, then its result should be accessible to prevent reinventing.

Organizational memory is not only as a tool and means to collect and preserve knowledge, but also is a means of sharing knowledge.

The results of the applying organizational memory is elevation of the related organization competition ability through improving management of its existing knowledge and exploring the experience gained from previous projects and reuse them to avoid repeating past mistakes.

Therefore, the organizational memory can be considered as a core of knowledge management system in an organization that personal and collective knowledge existing in an organization can be shared and reused by its creation (Ayazi and Shams Aleini, 2006, p. 3).

Following factors play a role in creation of organizational memory

1. The staff memory: part of the organization memory is in the minds of people who are willing to acquire knowledge based on experience. Experience is meant to examine and learn from what you examined which helps the staff to improve their performance in the organization. (Setej, 2000, p. 405)

2. Individual knowledge: individual knowledge critically depends on every individual within the organization that 
emerges in people following the experiences, skills, and personal knowledge, and it does not easily provide the explicit and objective expression. (Kiskin, 2008, p. 16)

3. Organization Culture: As personality (which means constant and stable series of characteristics) is defined for the individuals, personality can also be defined for organizations. Organizational culture is a set of basic assumption that is created, discovered, and developed by the organizational members in dealing with the problems, adaption to the environment and achievement to internal unity and cohesion and it has been proven that they are useful and valuable and therefore they transported to new members as the correct way of perception, thought and feeling. (Toosi, 2006, p. 3)

4. Information Technology: Technological knowledge is about ways of doing affairs. Technology is related to hardware and software computer for processing, storing and transmitting information. Information technology is the knowledge and skills in all aspects of computing, storage and retrieval of information and communication (Doroodchi, Nickmehr, 2014, p. 26)

5. Communications: is an exchange of messages, opinions, or attitudes that led to understanding between the sender and the receiver. Communication in organization and group plays four major efforts: control, incentives creation, emotions and information show, behavior of members can be controlled by the communication in several ways. Communications can improve incentive phenomenon. (Hoy and Miskel, translated by Syed Abbas Zadeh, 2008)

6. Organization Background: organizations like living organisms have a curve (periods) lifetime or life cycle. What organizations during each of the courses earn or lose is called organization background. (Edizes, Sirous translator, 2009, p. 104)

7. Organization Change and Transformation: change and conversion and transformation are generally transferred from an existing state to another state, whether pleasant or unpleasant. So changes may be positive and favorable or negative and unfavorable. (Aboudi, 2011, p. 89)

8. Organization structure: organizations determine necessity of formal coordination of organization member interaction patterns, organizational structure stipulates that how tasks are diagnosed, we know structure as a component of organization which has been composed of complexity elements of formalization, centralization. (Robbins, translated by Parsaeian and Aerabi, 2008, p. 159)

\section{Research Methodology}

The research method regarding to subject neutrality is survey. The statical population in this research is the staff whom worked in the education system in Mazandaran Province in 2004-2005. The number is 40823 persons, and sampling method is stratified random, and Cochran formula has been used to determine sample size.

According to this 381 persons have participated in this research. The questions' test was examined by utilizing from the opinions and guides of consultant and guide master to achieve the test validity in this study.

In this study by primary performance of questionnaires on 30 persons of expert masters has been conducted to determine reliability that questionnaires final coefficient has been achieved based on Cronbach's alpha of 0.801 in such a way that descriptive statistic was used to describe demographic characteristics, age kind, generic, education level, service experiment.

Frequency, percentage mean, minimum and maximum and diagrams in the inferential statistics level from multivariate regression test; factor analysis was used to achieve the relationship between variables with each other.

\section{Research Findings}

\subsection{Hypotheses}

1. Institutional memory management model in the education system is a linear and structural equation.

2. Credit rating of the proposed model from the viewpoints of experts, are confirmed more than $80 \%$ on average.

Table 1. Frequency distribution of population and sample

\begin{tabular}{|l|c|c|}
\hline & Number & Percentage \\
\hline Sample & 381 & $100 \%$ \\
\hline Population & 40823 & $100 \%$ \\
\hline
\end{tabular}


Table 2. Frequency distribution of education

\begin{tabular}{|c|c|c|c|}
\hline Group & Number & Percentage & Frequency Integration \\
\hline BS & 248 & $65 \%$ & 248 \\
\hline MSc & 118 & $31 \%$ & 366 \\
\hline PhD & 15 & $4 \%$ & 381 \\
\hline Total & 313 & $100 \%$ & - \\
\hline
\end{tabular}

Table 3. Frequency distribution of work experience

\begin{tabular}{|l|c|c|c|}
\hline Group & Number & Percentage & Frequency Integration \\
\hline 5 to 10 years & 95 & $25 \%$ & 95 \\
\hline 11 to 20 years & 172 & $45 \%$ & 267 \\
\hline 20 years and older & 114 & $30 \%$ & 381 \\
\hline Total & 381 & $100 \%$ & - \\
\hline
\end{tabular}

In response to the first hypothesis, first it is necessary impact of factors or capabilities to be assessed as a whole on memory management of the organization. Here this work was done by using multivariate regression. So amount of each of the underpinning variables - under study capabilities - were evaluated on the every single memory management capabilities of organization Shows amount of relationship between variables of technological meta-ability, organizational culture, organizational structure and meta-ability of organization background with the overall meta-ability of knowledge.

Table 4. Regression coefficient

\begin{tabular}{|l|c|c|c|c|c|}
\hline \multirow{2}{*}{ Model } & \multicolumn{2}{|c|}{ Not-Standardized coefficient } & Standardized coefficient & \multirow{2}{*}{ T statics } & \multirow{2}{*}{ Significant level } \\
\cline { 2 - 5 } & $\mathrm{B}$ & Error of criteria & beta & & 0.1 \\
\hline Meta-ability of technology & 071.0 & 035.0 & 391.0 & 042.0 \\
Organization culture & 172.0 & 042.0 & 341.0 & 1.4 & 000.0 \\
Organization structure & 048.0 & 047.0 & 359.0 & 0.2 & 003.0 \\
Meta-ability of organization background & 306.0 & 061.0 & 224.0 & 9.4 & 000.0 \\
\hline
\end{tabular}

Regarding to table 4 we found that: all changes include meaningful relationship and effective portion in specification of the amount of dependent variable changes and among them technological meta-ability is the most effective variable with the most amount of beta 0.39 , and organization structure with 0.36 and organizational culture with $34 \%$ and organization already meta-ability similarly with 0.22 are placed in next position. The variables are meaningful in the alpha level $1 \%$ and $5 \%$.Regarding to constituent capabilities, the process of organization memory management in educational system, should be investigated by the use of analysis technic of direct and indirect variables relationship in order to present the model, and also evaluated by using general and partial coefficients of investigated paths, in order to (independent) precede and transpose (dependent) the variables for prioritizing. To analyze the path first should determine main and effective variables by the use of regression coefficient of several variables and then respectively replacing the new variable, the amount of alpha, beta and t which has relationship with other dependent variables.

Based on the table 5 shows organization memory management as a general (dependent variable) for other variables.

Table 5. Regression coefficient

\begin{tabular}{|c|c|c|c|c|c|c|c|}
\hline \multirow{2}{*}{ Model } & \multirow{2}{*}{$f$} & \multirow[b]{2}{*}{$r$} & \multicolumn{2}{|c|}{ Not-Standardized coefficien } & \multirow{2}{*}{\begin{tabular}{|c|} 
Standardized coefficient \\
beta
\end{tabular}} & \multirow{2}{*}{ T statics } & \multirow{2}{*}{ Significant level } \\
\hline & & & $\mathrm{B}$ & Error of criteria & & & \\
\hline Meta-ability of technology & & & 278.0 & 064.0 & 268.0 & 3.4 & 000.0 \\
\hline Organization culture & & & 189.0 & 045.0 & 233.0 & 1.4 & 000.0 \\
\hline Organization structure & 000.0 & 77.0 & 114.0 & 036.0 & 201.0 & 1.3 & 002.0 \\
\hline Meta-ability of knowledge & & & 242.0 & 042.0 & 337.0 & 7.5 & 000.0 \\
\hline Meta-ability of organization background & & & 167.0 & 055.0 & 167.0 & 0.3 & 002.0 \\
\hline
\end{tabular}

Based on above table knowledge meta-capability with the alpha 0.000 and beta 0.34 , has the most amount of variance 
specification of organization memory management. Table 6 shows the meta-ability as a dependent variable for other variables.

Table5. Regression coefficient

\begin{tabular}{|l|c|c|c|c|c|c|}
\hline \multirow{2}{*}{ Model } & \multirow{2}{*}{$r$} & \multicolumn{2}{|c|}{ Not-Standardized coefficient } & Standardized coefficient & \multirow{2}{*}{ T statics } & Significant level \\
\cline { 3 - 6 } & & $\mathrm{B}$ & Error of criteria & beta & & \\
\hline Meta-ability of technology & & 261.0 & 064.0 & 228.0 & 2.4 & 000.0 \\
Organization culture & \multirow{2}{*}{59.0} & 179.0 & 045.0 & 243.0 & 3.4 & 000.0 \\
Organization structure & 126.0 & 036.0 & 218.0 & 9.2 & 000.0 \\
Meta-ability of organization background & & 159.0 & 055.0 & 157.0 & 1.2 & 001.0 \\
\hline
\end{tabular}

Based on above table organization culture with the alpha of 0.000 and beta of 0.24 has the most amount of variance specification of organization memory management. Hence is set as a dependent variable in the next step. Table 6 shows the dependent variable for the other variables.

Table 6. Regression coefficient

\begin{tabular}{|l|c|c|c|c|c|c|}
\hline \multirow{2}{*}{ Model } & \multirow{2}{*}{$\begin{array}{c}\text { Not-Standardized } \\
\text { coefficient }\end{array}$} & $\begin{array}{c}\text { Standardized } \\
\text { coefficient }\end{array}$ & $\begin{array}{c}\mathrm{T} \\
\text { statics }\end{array}$ & $\begin{array}{c}\text { Significant } \\
\text { level }\end{array}$ \\
\cline { 3 - 5 } & & $\mathrm{B}$ & Error of criteria & beta & & \\
\hline Meta-ability of Technology & & 278.0 & 064.0 & 268.0 & 3.4 & 000.0 \\
Organization culture & 62.0 & 114.0 & 036.0 & 181.0 & 1.3 & 002.0 \\
Organization structure & 167.0 & 055.0 & 167.0 & 0.3 & 002.0 \\
Meta-ability of organization background & & 16 & & & \\
\hline
\end{tabular}

Based on above table organization culture with the alpha 0.000 and beta 0.27 has the most amount of variance specification of organization memory management. Hence is set as a dependent variable in the next step. Table 7 shows the meta-ability as a dependent variable for other variables.

Table 7. Regression coefficient

\begin{tabular}{|c|c|c|c|c|c|c|}
\hline \multirow{2}{*}{ Model } & \multirow{2}{*}{$\mathrm{r}$} & \multicolumn{3}{|c|}{\begin{tabular}{|l|} 
Not-Standardized coefficient Standardized coefficient \\
\end{tabular}} & \multirow{2}{*}{ T statics } & \multirow{2}{*}{ Significant level| } \\
\hline & & $\mathrm{B}$ & Error of criteria & beta & & \\
\hline $\begin{array}{l}\text { Organization structure } \\
\text { Meta-ability of organization background }\end{array}$ & 68.0 & $\begin{array}{l}157.0 \\
154.0\end{array}$ & $\begin{array}{l}045.0 \\
031.0\end{array}$ & $\begin{array}{c}22.0 \\
167.0\end{array}$ & $\begin{array}{l}0.3 \\
1.1\end{array}$ & $\begin{array}{l}000.0 \\
000.0\end{array}$ \\
\hline
\end{tabular}

Based on above table organization culture with the alpha 0.000 and beta 0.22 has the most amount of variance specification of organization memory management. Hence is set as a dependent variable in the next step. Table 8 shows the already beta-ability as a dependent variable for other variables.

Table 8. Regression coefficient

\begin{tabular}{|l|c|c|c|c|c|c|}
\hline \multirow{2}{*}{ Model } & \multirow{2}{*}{$r$} & \multicolumn{2}{|c|}{ Not-Standardized coefficient } & Standardized coefficient & \multirow{2}{*}{ T statics } & \multirow{2}{*}{ Significant level } \\
\cline { 3 - 6 } & & $\mathrm{B}$ & Error of criteria & beta & & \\
\hline Meta-ability of Organazation background & 71.0 & 114.0 & 036.0 & 41.0 & 1.3 & 002.0 \\
\hline
\end{tabular}

Based on above already table beta-ability of organization with alpha 0.000 and beta 0.41 , it is obvious that there is strong relationship between these two variables. According to gained information of regression analysis and above path, the diagram is recovered as follows. 


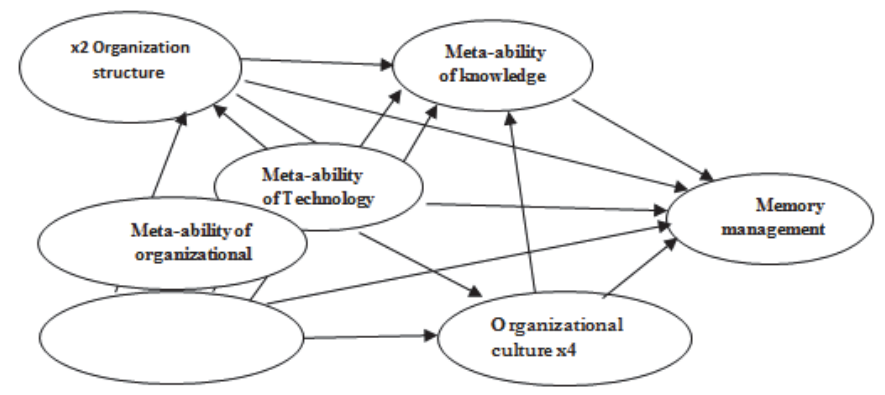

Figure 1. Analysis of achieved path of regression

To determine direct and indirect influence of each main variable $(\mathrm{x})$ and substituent $(\mathrm{y})$, following action was done: first main and direct influence of each variable is determined, then all indirect paths which lead the variable towards aimed variable, raising coefficient of each path is determined, sum of gained coefficients of indirect paths are considered as indirect variable.

Finally total of direct and indirect gained coefficients is determined as the amount of overall influence and is routed in terms of the case study action. Based on above diagram, the already organization beta-ability is considered as an end dependent variable regarding beta function and meaningful level. Based on mentioned information in diagram: Variable direct effect of meta- ability organization background on the memory management of organization

$\mathrm{p} 1.6=0.18$

Indirect effect $A=p 1.2 * \mathrm{p} 2.5 * \mathrm{p} 5.6=0.41 * 0.17 * 0.33=0.02$

$B=p 1.3^{*} p 3.5 * \mathrm{p} 5.6=0.22^{*} 0.23^{*} 0.33=0.01$

$\mathrm{C}=\mathrm{p} 1.5 * \mathrm{p} 5.6=0.15 * 0.33=0.04$

$\mathrm{D}=\mathrm{p} 1.4 * \mathrm{p} 4.6=0.16 * 0.23=0.03$

Total direct and indirect affect $0.02+0.01+0.04+0.03=0.1$

$0.1+0.18=0.28$

Variable direct effect the organization structure on the memory management of organization

p2.6 $=0 / 18$

Indirect effect

$A=p 2.3^{*} \mathrm{p} 3.4^{*} \mathrm{p} 4.6=0.16^{*} 0.26^{*} 0.23=0.09$

$B=p 2.3 * \mathrm{p} 3.5 * \mathrm{p} 5.6=0.16 * 0.23 * 0.33=0.01$

$C=p 2.3 * \mathrm{p} 3.6=0.16 * 0.26=0.04$

$\mathrm{D}=\mathrm{p} 2.5^{\star} \mathrm{p} 5.6=0.17^{\star} 0.33=0.06$ Total direct and indirect effect

$0.06+0.09+0.01+0.04=0.2$

$0.2+0.18=0.38$

Variable direct effect the organization structure on the memory management of organization p3.6 $=0 / 27$

Indirect effect $A=p 3.5 * p 5.6=0.23 * 0.33=0.07$

$B=p 3.4^{*} p 4 \cdot 6=0.26 * 0.23=0.005$

$\mathrm{C}=\mathrm{p} 3.4^{*} \mathrm{p} 4.5^{*} \mathrm{p} 5.6=0.26^{*} 0.14^{*} 0.33=0.01$

Total direct and indirect affect $0.07+0.005+0.01=0.13$

$0.13+0.27=0.40$

Variable direct effect the organization structure on the memory management of organization

p4.6 $=0.40$

Indirect effect

$\mathrm{A}=\mathrm{p} 4.5 * \mathrm{p} 5.6=0.14 * 0.33=0.04$

Total direct and indirect affect $0.04+0.30=0.44$

Variable direct effect the organization structure on the memory management of organization

According to the above diagram and the effectiveness amount of each of capabilities on organizational memory management, can be now presented following model. 


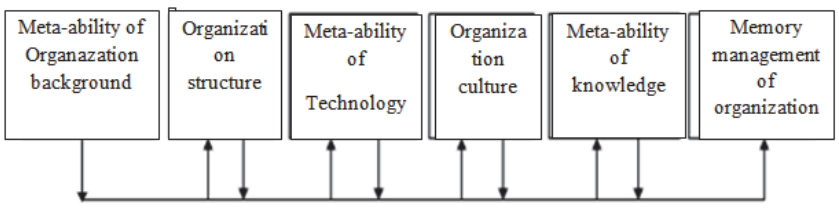

Figure2. Organizational memory management model in education system

Second hypothesis: in average the more 80 percent of educational experts confirm the proposed model in the study.

In special vector method, always achieved weight by using special vector method represents the numbers correlation obtained of this method and the correlation is significant. In accordance with the following dimensions, were asked the experts to allocate points of 9, 7,5,3,1 to each dimension with respect to the questions. Standard rating to dimensions is as follows: Very low, low, medium, high, very high, then, according to the special vector method achieved dimensions weights and at the end according to the results obtained was calculated rating to model. Table 9 shows the dimensions of the average rating in viewpoint of expert.

Table 9. External evaluation scores of the proposed model

\begin{tabular}{|c|l|c|c|}
\hline Row & Dimensions & Mean & Weighted average \\
\hline $\mathbf{1}$ & Philosophical Foundations & 1.8 & 51.0 \\
\hline $\mathbf{2}$ & of objectives & 5.8 & 69.1 \\
\hline $\mathbf{3}$ & Theoretical foundations & 4.8 & 56.0 \\
\hline $\mathbf{4}$ & Conceptual Framework & 2.8 & 68.0 \\
\hline $\mathbf{5}$ & Compatibility of objectives, with components & 5.8 & 21.0 \\
\hline $\mathbf{6}$ & Accuracy of Primacy and regency of components & 7.8 & 48.0 \\
\hline $\mathbf{7}$ & Compatibility with existing literature. & 3.8 & 16.0 \\
\hline $\mathbf{8}$ & Components of objective & 2.9 & 00.1 \\
\hline $\mathbf{9}$ & Ability to update & 1.9 & 33.0 \\
\hline $\mathbf{1 0}$ & Applicable & 4.8 & 20.0 \\
\hline
\end{tabular}

Based on above table model 8.44 is from 9 . If we will calculate the validity percent it would be $84 \%$ which is appropriate percent, therefore the proposed model is valid and it means that educational experts confirmed the proposed model of organization memory management.

Table 10 shows the evaluation matrix of internal correlation of proposed model of organization memory management in educational system.

Table 10. Evaluation matrix of internal correlation of proposed model of organization memory management in educational system

\begin{tabular}{|c|c|c|c|c|c|c|c|c|c|c|}
\hline & 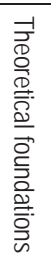 & $\begin{array}{l}\stackrel{0}{0} \\
\frac{\mathscr{O}}{\omega}\end{array}$ & 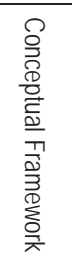 & 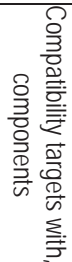 & 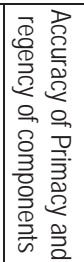 & 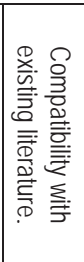 & 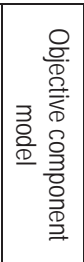 & 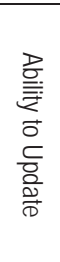 & 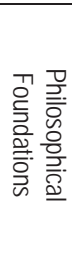 & 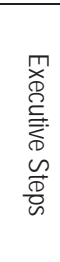 \\
\hline Theoretical foundations & & 41.0 & 43.0 & 25.0 & 29.0 & 21.0 & 20.0 & 24.0 & 45.0 & 21.0 \\
\hline Goals & & & 37.0 & 27.0 & 39.0 & 30.0 & 41.0 & 24.0 & 31.0 & 33.0 \\
\hline Conceptual Framework & & & & 31.0 & 36.0 & 27.0 & 35.0 & 21.0 & 29.0 & 31.0 \\
\hline Compatibility targets with, components & & & & & 24.0 & 41.0 & 30.0 & 33.0 & 26.0 & 21.0 \\
\hline Accuracy of Primacy and regency of components & & & & & & 31.0 & 27.0 & 31.0 & 34.0 & 21.0 \\
\hline Compatibility with existing literature. & & & & & & & 24.0 & 21.0 & 21.0 & 33.0 \\
\hline Objective component model & & & & & & & & 21.0 & 21.0 & 31.0 \\
\hline Ability to Update & & & & & & & & & 26.0 & 36.0 \\
\hline Philosophical Foundations & & & & & & & & & & 27.0 \\
\hline Executive Steps & & & & & & & & & & \\
\hline
\end{tabular}


Based on above table, there is an applicability of acceptable correlation between the proposed model dimensions include philosophical principal dimension, goals, theoretical principals, perceptive frame, goal adaptation with components, accuracy of precedence and transposition of model components, adaptation with exist literature, its concrete components. The amount of internal correlation of proposed model components are respectively $0.45,0.41,0.41,0.43$, $0.25,0.29,0.21,0.20,0.24,0.21$.

The amount of correlation is lower than other cases, but this amount is acceptable regarding to be meaningful. Thus regarding to above tables include the components of internal correlation and indifferently $84 \%$ of educational experts confirm the proposed model.

\section{Discussion and Conclusion}

The main purpose of this research is to design organizational memory management in the education system. Organizational memory management model in the supreme education system based on the organizational memory and knowledge knows organizational memory management due to interaction. This model with a set of abilities in the education system wants to provide empowerment bed for organizational memory system.

Therefore, the education is purposed; in such a way that its strategies and procedures encourage its members regarding to organization memory so that the organizational memory management be done. This model differentiation is in place selection.

Chandler (1997), historian business says that technology improvement in 19th century has been a production of organizations visible hands, not market invisible hands, and the education system has an important role in scientific knowledge improvement amongst these organizations; also north, famous economic historian (1990) states that 19th century creative energy improved mostly in social institutions not in industry, science or art; name of the educations, universities, research institutions is seen among these institutions and lack of efficient institutions led to lag between industrial revolutionary commence and technical economy development in the late 19th century.

Currently it is believed that the education system helps to develop regional economy development increasingly. Therefore it is necessary that the education plays a leader role in programming and performance, so it implicates their involvement with organizational memory management.

Regarding to above discussion, organization memory management model suggestion for the education system can be a suitable means for the realizations of these ideals. Of course this model use requires some changes in the education system design because its current bureaucratic structure, its technologic knowledge, non-attention to the staff memory, and the knowledge cohered to the staff does not have organizational memory management ability and its knowledge; But is required a new flexible design that facilitates the organizational memory management. Therefore shows the proposed model framework to develop the relationships between concepts and variables. In fact, they are a diagram or a plan which relate concepts together and show them in a reliable and rational structure.

\section{References}

Akhavan Kharaziyan, M, (2013) design model organizational memory prerequisite knowledge management and its impact on the performance, financial management Development Conference, March 2013 Tehran

Asadpour, kh, et al., (2014) .systm institutional memory tool for learning staff in the areas of innovation, business excellence Vkaraqtsad international conference on development and management, Tehran

Arbab shirani, B (2009). Explain the necessary elements to create knowledge, and to determine methods of measurement and evaluation. Tarbiat Modarres University engineering doctoral dissertation.

Ansari Harsini, A (2010), knowledge of culture, comparing the culture of knowledge and research and planning of radio and television and the airline industry of the country, senior thesis, Institute of Education and Research Planning.

Thmoghaddam A, (2010), a model for the development of knowledge management in research organizations with a view to the effective use of ICT, the Fifth Conference of Industries and Mines R \& D centers, Tehran

Adyzi moghaddam, A., (2011), the life cycle, translator Kaveh Mohammad Cyrus, Amir Kabir Publications

F, Ayyazi, et al. (2010), the use of institutional memory in order to refine the architecture of the second International Conference on Technology Management and Development, Tehran

Dalkeir Keimz (2013), knowledge management theory and practice of translation Saeed Pour publications Rzgr Tehran

M, Drudchi, Nikmehr n., (2014), the importance of technology in the management estimates, the National Congress of Trade, Tehran

Robbins, Stephen P. (2008), the theory of the structure and organizational design, translation Mehdi Alvani, good knowledge of, Tehran Safar Publications -Ashraqy p. 45-48

Robbins, Stephen P. (2009), Principles of Organizational Behavior, translated by Ali Parsaeian, Mohammad Arabs, Tehran Publications Cultural Research Bureau S203-235 
Tusi, Muhammad ali; (2006), organizational culture, Tehran, Public Administration Training Center, the twentieth edition, p. 3.

Ayoudi G., (1390) structural bottlenecks in science and technology and successful technology transfer strategies, approaches Magazine, Issue 20, pp. 5-29

Abdoli, F. (2008). KM towards Fradansh.thran: cognitive thought, 36-135

Niaz Azeri, K, et al., (2011), the theory of organization and management in the Third Millennium Press, Tehran

Hoy, Myskl.j. (2008), theory, research and practice in the management, translation Myrmhmdsydbas born, the process of Urmia University Press, pp. 12-15 (17(

Akgon .g, and et all (2011) «The paradox of using tactic explicit knowledge strategies to face dilemmas», Management Decision Journal, Vol, 43.No, 1.

Anad, Joaguin; Lapiedra, Rafael \& Chiva, Richard. (2012). "A measurement scale for product innovation performance". European Journal of Innovation Management, 1 (0), pp. 333-301.

Argote, I \& A., enegram, S. (2008). "Towards a multidisciplinary definition of innovation". Management Decision 07 (8): 1323-1336.

Dieng R. et al., 2004, "Methods and Tools for Corporate Knowledge Management", Proceedings of KAW'91, Eleventh Workshop on Knowledge Acquisition, Modeling andManagement, Canada

Keskin, Halit (2008) "The Relationship between explicit and tacit orientaed knowledge strategy and firm performance", Journal of American Academy of Business ". Vol.1

kessi, tomi, Fernando jenson.k, (2003) "reconfiguring knowledge management- combining intellectual capital, intangible assets and knowledge creation" .Journal of Knowledge Management Vo. 8, No.2, pp.36-52

Koistinen, P. \& Virolainen, M. Veli. (2001), "Promoting (managing) Organizational Memory in Partnership"; info. / ut.fi / katilot / peko / orgem, pdf.

Markos, A.S. Miner (2011). "Organizational Improvisation and Organizational Memory". Academy of Management Review: 168-723

Stein.e.v. "Organizational Memory: Review of Concepts and Recommendations for Management". International Journal of Information Management. 2001, 11 (2), 19-32.

Virani Tazilm; Louise Lemieux Charles; DavidA. Davis and WhitneyBerta (2010). "Sustaining Change: Once Evidencec Based Practices Are Transferred, What Then" Healthcare Quarterly, Vol.12 No.1

Zadayannaya Liudmila, (2012), "Organizational Memory systems As a Source of Learning for New Employees in an Innovation Context" School of Business and Engineering 